\title{
Technical note: Fu-Liou-Gu and Corti-Peter model performance evaluation for radiative retrievals from cirrus clouds
}

\author{
Simone Lolli ${ }^{1,2}$, James R. Campbell ${ }^{3}$, Jasper R. Lewis ${ }^{1}$, Yu Gu ${ }^{4}$, and Ellsworth J. Welton ${ }^{5}$ \\ ${ }^{1}$ NASA GSFC-JCET, Code 612, 20771 Greenbelt, MD, USA \\ ${ }^{2}$ CNR-IMAA, Istituto di Metodologie per l'Analisi Ambientale, Potenza, Italy \\ ${ }^{3}$ Naval Research Laboratory, Monterey, CA, USA \\ ${ }^{4}$ UCLA, Los Angeles, CA, USA \\ ${ }^{5}$ NASA GSFC, Code 612, 20771 Greenbelt, MD, USA
}

Correspondence to: Simone Lolli (slolli@umbc.edu)

Received: 5 November 2016 - Discussion started: 15 December 2016

Revised: 16 May 2017 - Accepted: 16 May 2017 - Published: 14 June 2017

\begin{abstract}
We compare, for the first time, the performance of a simplified atmospheric radiative transfer algorithm package, the Corti-Peter (CP) model, versus the more complex Fu-Liou-Gu (FLG) model, for resolving top-of-theatmosphere radiative forcing characteristics from singlelayer cirrus clouds obtained from the NASA Micro-Pulse Lidar Network database in 2010 and 2011 at Singapore and in Greenbelt, Maryland, USA, in 2012. Specifically, CP simplifies calculation of both clear-sky longwave and shortwave radiation through regression analysis applied to radiative calculations, which contributes significantly to differences between the two. The results of the intercomparison show that differences in annual net top-of-the-atmosphere (TOA) cloud radiative forcing can reach $65 \%$. This is particularly true when land surface temperatures are warmer than $288 \mathrm{~K}$, where the $\mathrm{CP}$ regression analysis becomes less accurate. $\mathrm{CP}$ proves useful for first-order estimates of TOA cirrus cloud forcing, but may not be suitable for quantitative accuracy, including the absolute sign of cirrus cloud daytime TOA forcing that can readily oscillate around zero globally.
\end{abstract}

\section{Introduction}

Cirrus clouds play a fundamental role in atmospheric radiation balance and their net radiative effect remains unclear (IPCC, 2014; Berry and Mace, 2014; Campbell et al., 2016; Lolli et al., 2017). Feedbacks between cirrus dynamic, microphysical and radiative processes are poorly un- derstood, with ramifications across a host of modeling interests and temporal/spatial scales (Kuo-Nan, 1986; Liou, 1986, Khvorostyanov and Sassen, 1998). Simply put, different models parameterize ice formation in varied, yet relatively simplified, ways that impact how cirrus are resolved, and how their macro/microphysical and radiative properties are coupled with other atmospheric processes (e.g., Comstock et al., 2001; Immler et al., 2008). Consequently, models are very sensitive to small changes in cirrus parameterization (Soden and Donner 1994; Min et al., 2010; Dionisi et al., 2013).

Cirrus clouds constitute the only tropospheric cloud genus that exerts either a positive or negative top-of-the-atmosphere (TOA) cloud radiative forcing effect (CRE) during daytime. All other clouds exert a negative daytime TOA CRE. Cirrus clouds exerting negative net TOA CRE cool the earthatmosphere system and surface below them. This occurs as the solar albedo term is greater than the infrared absorption and re-emission term. Positive forcing occurs when the two are reversed and infrared warming and re-emission exceed scattering back to space. In contrast, all clouds cause a positive nighttime TOA value, with an infrared term alone and no compensating solar albedo term. This dual property makes cirrus distinct, and why it is crucial to understand how well radiative transfer models are resolving their TOA CRE properties.

The burgeoning satellite and ground-based era of atmospheric monitoring (Sassen and Campbell, 2001; Campbell et al., 2002; Welton et al., 2002; Nazaryan et al., 2008; Sassen 
et al., 2008) has led to a wealth of new data for looking at global cirrus cloud properties. In particular, TOA CREs are evaluated by means of radiative transfer modeling, designed with different degrees of complexity. What is not yet known is how the relative simplicity of some models translates to a relative retrieval uncertainty, given that the CRE effect of cirrus clouds, at both the ground and TOA, is typically on the order of $1 \mathrm{~W} \mathrm{~m}^{-2}$ (e.g., Campbell et al., 2016; Lolli et al., 2017). Whereas some studies show the relative uncertainty of such models as static percentages (Corti and Peter, 2009), the absolute magnitude of uncertainty with respect to cirrus CRE is necessary to understand whether or not they fit within acceptable tolerance thresholds sufficient for quantitative use. Further, given the sensitivity in the sign of net annual cirrus cloud daytime TOA CRE specifically (Campbell et al., 2016), it is plausible that some simpler models are routinely aliasing positive versus negative TOA CRE.

Corti and Peter (2009; CP) describe a simplified radiative transfer model that relies upon a constrained number of input parameters, including surface temperature, cloud top temperature, surface albedo, layer cloud optical depth, and the solar zenith angle. CP simplifies drastically the framework of the $\mathrm{Fu}$-Liou-Gu radiative transfer model (Fu and Liou, 1992; Gu et al., 2003, 2011; FLG), for instance, through a parameterization of the longwave and shortwave fluxes derived from the FLG model calculations for realistic atmospheric conditions. Moreover, CP does not directly consider gaseous absorption. The model has increasingly been used to assess cirrus cloud radiative effects (Kothe et al., 2011; Kienast-Sjögren et al., 2016; Burgeois et al., 2016) from lidar measurements, owing to its relative simplicity and lower computational burden compared with a model like FLG.

To date, CP model performance vs. FLG model has been evaluated for sensitivities only to simulated synthetic clouds and never on real measurements, especially those collected over long periods (Corti and Peter, 2009). Such evaluation, however, can readily be conducted using the unique NASA Micro-Pulse Lidar Network (MPLNET; Welton et al., 2002; Campbell et al., 2002; Lolli et al., 2013, 2014), established in 1999 to continuously monitor cloud and aerosol physical properties (Wang et al., 2012; Pani et al., 2016).

The objective of this technical note is to then assess differences between CP and FLG in terms of net annual daytime TOA CRE. CP and FLG model performance are evaluated using MPLNET datasets collected from Singapore in 2010 and 2011, a permanent tropical MPLNET observational site, and at Greenbelt, Maryland, in 2012, a midlatitude site. Our goal is to more appropriately characterize the sensitivities of CP relative to what is generally considered a more complex, and presumably more accurate, model, with the hopes of better understanding relative uncertainties and thus interpreting whether such uncertainties are appropriate for longterm global cirrus cloud analysis.

\section{Method}

FLG is a combination of the delta four-stream approximation for solar flux calculations (Liou, 1986) and a delta-twofour-stream approximation for IR flux calculations (Fu et al., 1997), divided into 6 and 12 bands, respectively. It has been extensively used to assess net cirrus cloud daytime radiative effects, most recently for daytime TOA forcing characteristics within MPLNET datasets at both Greenbelt, Maryland, and Singapore, respectively (Campbell et al., 2016; Lolli et al., 2017). The results from these studies have led to the hypothesis of a meridional gradient in cirrus cloud daytime TOA radiative forcing existing, with daytime cirrus clouds producing a positive daytime TOA CRE at lower latitudes that reverses to a net negative daytime TOA CRE approaching the non-snow and ice-covered polar regions. They estimate absolute net cirrus daytime TOA forcing term between 0.03 and $0.27 \mathrm{~W} \mathrm{~m}^{-2}$ over land at the mid-latitude site, which ranges annually between 2.20 and $2.59 \mathrm{~W} \mathrm{~m}^{-2}$ at Singapore. The key here to this phenomenon is the possible oscillation of the net daytime TOA CRE term about zero, which is believed to vary by a maximum $\pm 2 \mathrm{~W} \mathrm{~m}^{-2}$ in absolute terms (i.e., normalized for relative cirrus cloud occurrence rate), after accounting for polar clouds that should be net cooling elements and varying surface albedos over land and water exclusively (i.e., not ice). Resolving such processes thus requires relatively high accuracy in radiative transfer simulations.

To calculate daytime cirrus cloud radiative effects from MPLNET datasets, the lidar-retrieved single-layer cirrus cloud extinction profile (Campbell et al., 2016; Lewis et al., 2016; Lolli et al., 2016, 2017) is transformed into crystal size diameter (using the atmospheric temperature profile) and ice water content (IWC) profiles using the parameterization proposed by Heymsfield et al. (2014). Those parameters, at each range bin, are input into FLG. The thermodynamic atmospheric profiles, together with ozone concentrations are obtained with a temporal resolution of $\pm 3 \mathrm{~h}$, from a meteorological reanalysis of the NASA Goddard Earth Observing System Model version 5.9.12 (GEOS-5). In contrast, for a given cloud case, the corresponding cloud and atmospheric $\mathrm{CP}$ input parameters are explicitly the land/ocean surface temperature, the cloud top temperature, the surface albedo, the cloud optical depth for the specific layer, and the solar zenith angle.

Calculations here are performed for the same MPLNET observational sites, Singapore and Greenbelt, Maryland (i.e., NASA Goddard Space Flight Center; GSFC). For the former site, two different values of the surface albedo, which is a common input parameter in both models, are fixed at 0.12 and 0.05 , respectively, as Singapore is a metropolitan area completely surrounded by sea. This allows us to more reasonably characterize forcing over the broader archipelago of Southeast Asia, and follows the experiments described by Lolli et al. (2017). At NASA GSFC, only a single over-land 
albedo is used, though one that varies monthly between 0.12 and 0.15 based on climatology.

Here, we reconsider these results by first intercomparing those solved with FLG and CP for net daytime TOA CRE over a practical range of cloud optical depth (COD). As described in both Campbell et al. (2016) and Lolli et al. (2017), daytime is specifically defined in these experiments as those hours where incoming net solar energy exceeds that outgoing. Only under such circumstances can the net TOA CRE term become negative. Otherwise, it is effectively nighttime, as the term is positive and all clouds induce a warming TOA term. Those nighttime results presented within the analysis below will instead be considered as context for understanding net diurnally averaged differences between the models specifically for the GSFC dataset.

\section{Intercomparisons}

The daytime cirrus net TOA CRE, normalized by corresponding occurrence frequency, in this case as a function of COD, was evaluated at Singapore $\left(1.3^{\circ} \mathrm{N}, 103.8^{\circ} \mathrm{E}\right.$; $20 \mathrm{~m}$ above mean sea level, $\mathrm{m}$ a.m.s.l. $)$ and GSFC $\left(38.9^{\circ} \mathrm{N}\right.$, $76.8^{\circ} \mathrm{W}$; 39 m a.m.s.l.) for both FLG and CP. The method to estimate MPLNET cirrus cloud optical properties is described in Lewis et al. (2016) and Campbell et al. (2016), for both 20 and $30 \mathrm{sr}$ solutions from the unconstrained singlewavelength elastic lidar equation at $532 \mathrm{~nm}$ (Campbell et al., 2016). The latter constraint provides "bookend" estimates for TOA CRE designed to approximate system variance. For both models, the daytime cirrus cloud net TOA CRE is calculated as the difference of two model computations using different assumed states (cloudy sky minus cloud and aerosol particulate-free conditions) to isolate the distinct cirrus cloud impact alone (in $\mathrm{W} \mathrm{m}^{-2}$ ).

\subsection{Model sensitivities}

An initial sensitivity study was carried out to evaluate how the input parameters, and eventually their uncertainties, influence the net TOA CRE calculations. Results are summarized in Table 1. Model input parameter sensitivities were investigated for surface albedo, COD, land/ocean surface temperature, and cloud top temperature. Table 1 shows how much net, SW, and LW fluxes change by varying each individual parameter alone. For instance, changing the surface albedo from 0.12 to 0.14 and keeping the other three parameters fixed produces similar changes in both models ( $26 \%$ for $\mathrm{CP}$ model and $25 \%$ for FLG model). Changing COD from 1 to 1.1 produces a change of $16 \%$ for CP and $21 \%$ for FLG. Changing surface temperature and cloud top temperature of $1 \mathrm{~K}$ produces respective changes of 10 and $7 \%$ for $\mathrm{CP}$ and 7 and $6 \%$ for FLG. Though subtle, the models exhibit some differences in variance relative to the input parameters required to initialize them.

\subsection{Singapore (2010-2011)}

FLG and CP were compared over a total of 33072 total daytime single-layer cirrus clouds at Singapore from 2010 to 2011. Figures 1, 2, 3, and 4 reflect histograms of cirrus cloud relative frequency and net annual daytime TOA CRE normalized by corresponding frequency, for surface albedo values of both 0.05 (Figs. 3 and 4; i.e., over sea) and 0.12 (Figs. 1 and 2; i.e., over land) at $0.03 \mathrm{COD}$ resolution from 0 to 3 . This latter COD range was chosen to distinguish cirrus clouds in a phenomenological manner consistent with Sassen and Cho (1992). Note that, since a common cloud sample is used, the $20 \mathrm{sr}$ samples vary in COD between only 0 and approximately 1 in contrast to the $30 \mathrm{sr}$ sample topping out at 3 . The observed differences in net radiative effect can be ascribed to the different lidar ratio. Overall, the results here complement the work of Berry and Mace (2014), who first recognized the significance of optically thin cirrus influencing the net normalized term so significantly.

Intercomparison of net daytime TOA CRE vs. COD over the ocean at $30 \mathrm{sr}$, we obtain -0.89 from $\mathrm{CP}$ and $-0.37 \mathrm{~W} \mathrm{~m}^{-2}$ for FLG. The overall CP net TOA CRE is greater in absolute magnitude than FLG by a maximum difference of $58 \%$. This value is obtained by taking the ratio between yearly CRE from FLG over CP and then the percentage difference. Over land (urban environment), $\mathrm{CP}$ net daytime TOA CREs are higher than the FLG model by $25 \%\left(\mathrm{CP}=4.43\right.$ and $\left.\mathrm{FLG}=3.35 \mathrm{~W} \mathrm{~m}^{-2}\right)$. The $\mathrm{COD}$ value at which cirrus begin cooling the earth-atmosphere system, moving toward higher COD, is systematically shifted towards higher values for CP with respect to FLG.

To better understand the different outputs between the two models, a scatter plot between from FLG barplot entries is shown in Figs. 2 and 4, and the corresponding CP barplot values are plotted, over land and over ocean, in Figs. 5 and 6. The blue line represents the actual linear data regression, while the red line represents an ideal case (i.e., slope $=1$, intercept $=0$ ). If the two radiative transfer models show identical results regarding CRE, all the points should lie on the blue line. The red line instead represents the actual regression line, or a relative measure of how much the two models differ.

From Figs. 5 and 6, the FLG-derived net daytime CP TOA CRE values are systematically greater in absolute value than the corresponding FLG values by $60 \%$. More in detail, CP TOA CRE of $1 \mathrm{Wm}^{-2}$ corresponds with FLG values ranging from 0.57 to $0.59 \mathrm{Wm}^{-2}$. However, the bias (or the intercept from the linear regression) shows higher variability depending on the surface type underlying the cirrus cloud (land versus ocean). This indicates that when a cirrus cloud shows a neutral effect $\left(0 \mathrm{Wm}^{-2}\right)$ for CP model, FLG model solutions range from -0.05 (land) to $-1.1 \mathrm{Wm}^{-2}$ (ocean). This implies that characterization of cirrus cloud warming or cooling effects depend on the model. 
Table 1. Total NET, SW, and LW fluxes $\left(\mathrm{W} \mathrm{m}^{-2}\right.$ ) at TOA. Sensitivities of CP and FLG radiative transfer models with respect to the surface albedo, cloud optical depth, and unperturbed parameters are COD $=1$, surface albedo $=0.12, T_{\text {surf }}=294 \mathrm{~K}$, and cloud top $T_{\text {top }}=229 \mathrm{~K}$. The variations in net radiative forcing expressed in percentage for each parameter are calculated changing the surface albedo from 0.12 to 0.14 , the COD from 1 to 1.1 , and augmenting the temperatures of $1 \mathrm{~K}$.

\begin{tabular}{lrrrrrl}
\hline NET CP & NET FLG & LW TOA FLG & SW TOA FLG & LW TOA CP & SW TOA CP & Parameters \\
\hline-12.6 & -9.4 & 67.8 & -77.2 & 69 & -81.6 & Ref \\
$9.3(26 \%)$ & $-7(25 \%)$ & 67.8 & -74.8 & 69 & -78.3 & Albedo \\
$-14.7(16 \%)$ & $-11.4(21 \%)$ & 71.8 & -83.2 & 73.5 & -88.2 & Cod \\
$-11.3(10 \%)$ & $-8.7(7 \%)$ & 68.5 & -77.2 & 70.3 & -81.6 & Surf Temp \\
$-13.5(6 \%)$ & $-10(5 \%)$ & 67.2 & -77.2 & 68.1 & -81.6 & Cl Top Temp \\
\hline
\end{tabular}
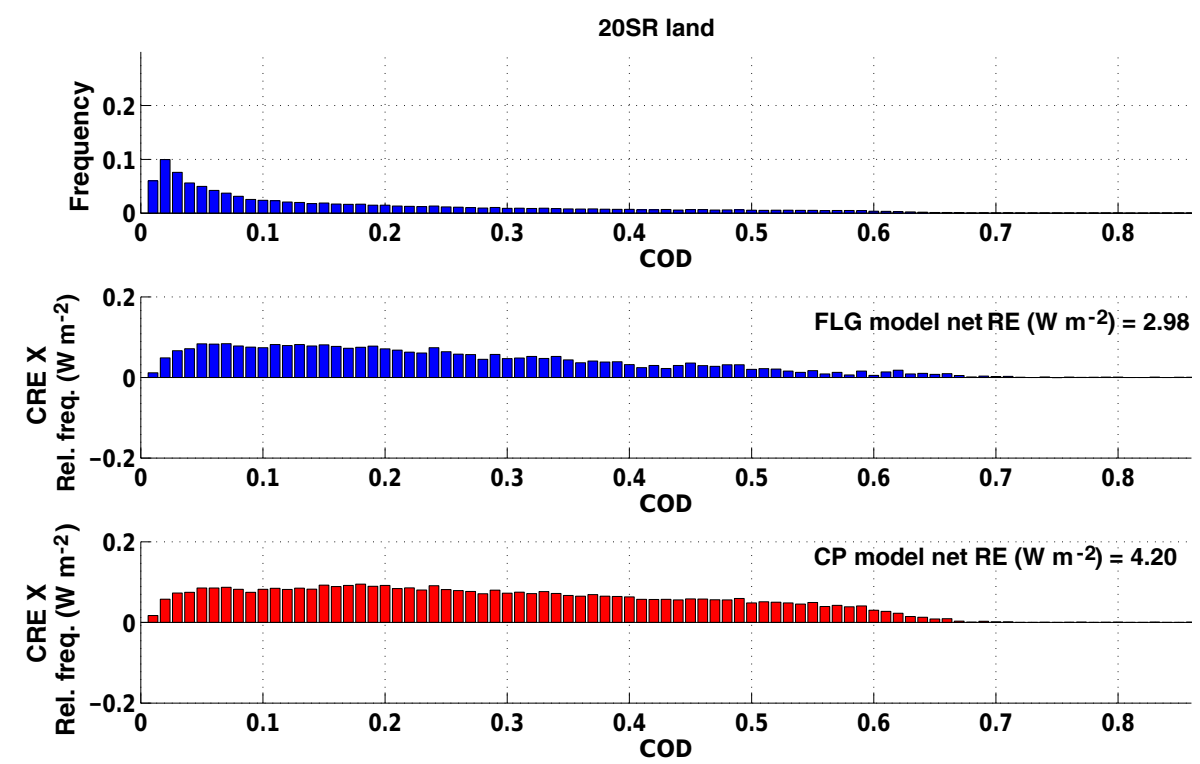

Figure 1. Analysis over land (albedo $=0.12$ ) for 20 sr solution. CRE vs. COD is weighted by occurrence frequency for Corti and Peter (red) and FLG (blue) models over 2010-2011.

For the sake of completeness, and to cover all the variability related to the chosen LR, we performed the same analysis though excluding the $20 \mathrm{sr}$ solution. Over the ocean, we derive an overall forcing of 1.34 for $\mathrm{CP}$ and $0.48 \mathrm{~W} \mathrm{~m}^{-2}$ for FLG (41\%). In Fig. 3 (blue arrow), a shift is clearly evident near 0.25 COD ( 0.6 for CP and 0.35 for FLG) in CRE sign change (from positive to negative). Over land, we estimated $\mathrm{CP}=4.20$ and $\mathrm{FLG}=2.98 \mathrm{~W} \mathrm{~m}^{-2}(68 \%)$.

\subsection{Greenbelt, Maryland, 2012}

To limit potential assessment ambiguity based on a singlesite analysis, we performed a second model comparison using the 2012 NASA GSFC dataset. A summary of this dataset and net daytime TOA CRE results can be found in Campbell et al. (2016). As this site is land-locked, only the single albedo was, again, used, though varied monthly based on climatological passive satellite estimates. A total of 21107 daytime cirrus cloud profiles were considered. Shown in Fig. 6 (upper panel) are the total net TOA CREs vs. COD at $30 \mathrm{sr}$, for $\mathrm{CP}\left(-2.59 \mathrm{Wm}^{-2}\right)$ against FLG $\left(0.05 \mathrm{Wm}^{-2}\right)$. A relative differencing here is impractical. However, this is a significant difference, and the sign of the net daytime forcing term is uncertain when comparing the two.

With this NASA GSFC dataset, we further consider an additional 32185 nighttime cirrus cloud cases within the analysis (Fig. 6, lower panel). Relative to prior estimates of CP uncertainty compared with more complex models, a diurnal average would be likely to produce a different, and plausibly closer, relative agreement consistent with prior studies. That is, since during for most of the period we define here as night there is no solar input, a simplification of the infrared forcing terms and parameterizations alone would potentially yield a closer comparison between the two models. For the NASA GSFC dataset, we solved a relative net nighttime TOA CRE of $29.1 \mathrm{Wm}^{-2}$ with FLG compared with $21.0 \mathrm{Wm}^{-2}$ with $\mathrm{CP}$, or a relative difference approaching $50 \%$. Summa- 

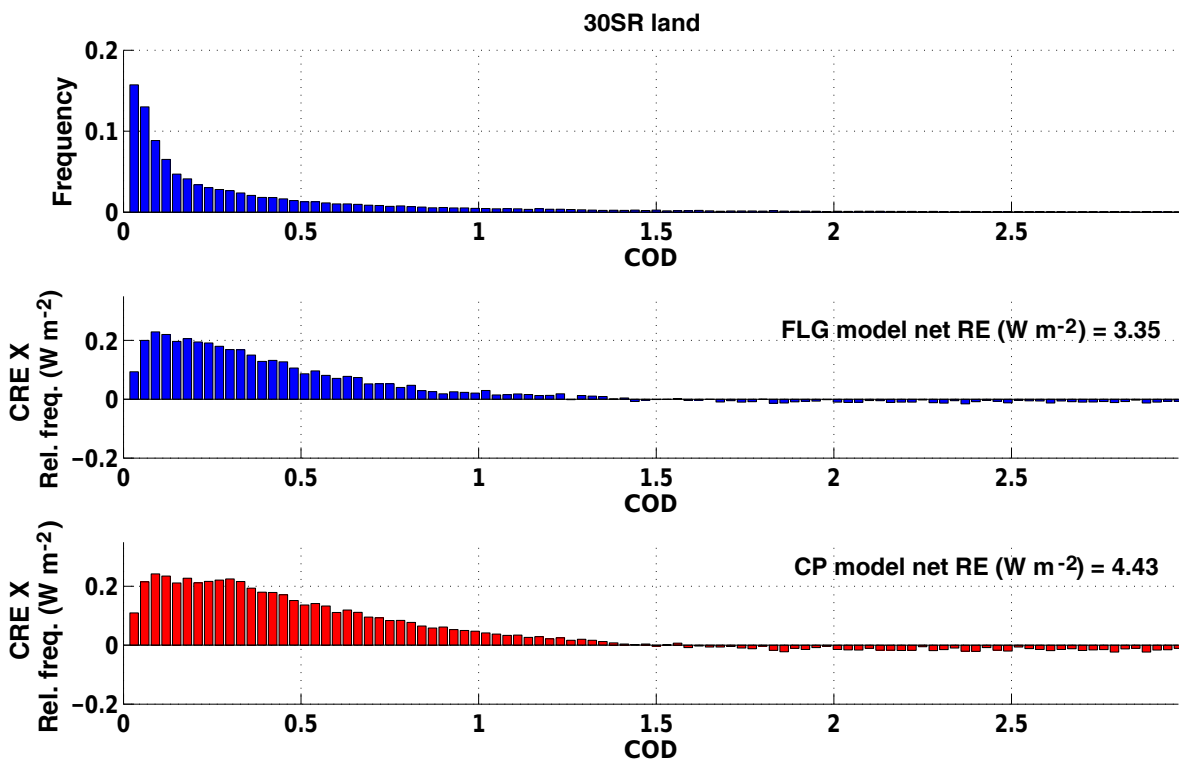

Figure 2. Analysis over land (albedo $=0.12$ ) for $30 \mathrm{sr}$ solution. CRE vs. COD is weighted by occurrence frequency for Corti and Peter (red) and FLG (blue) models on 2010-2011.
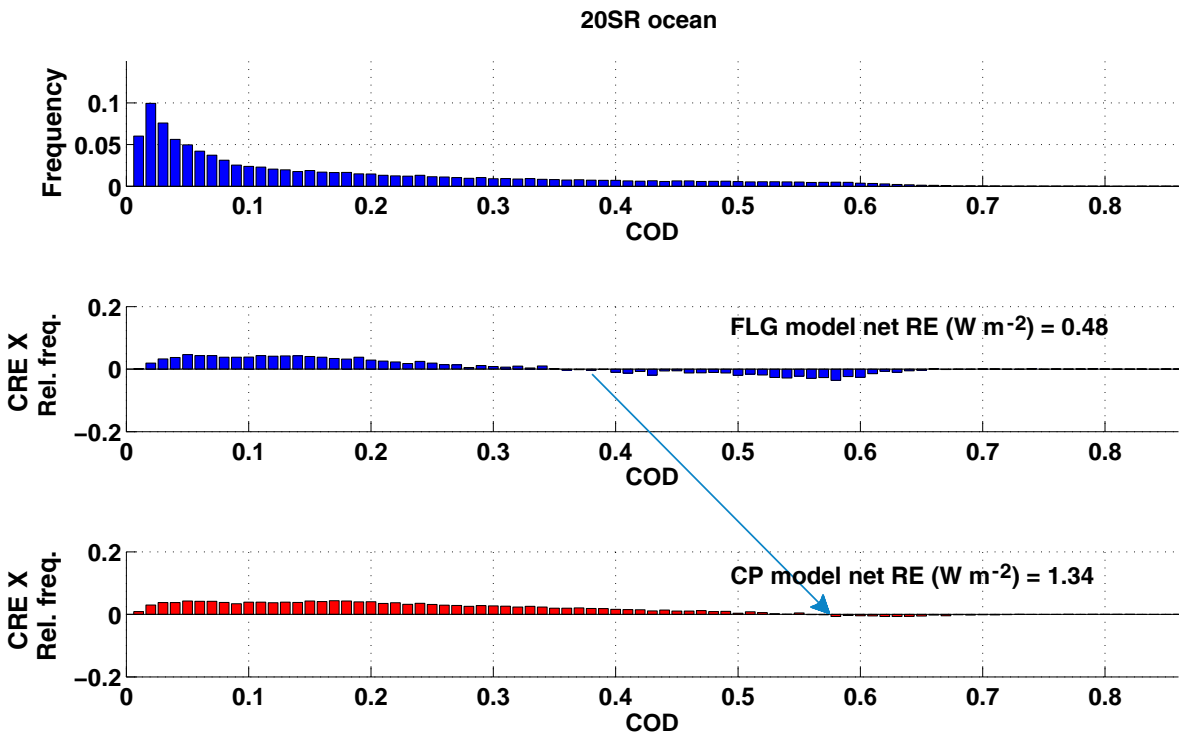

Figure 3. Same as Fig. 1, but over the ocean (albedo=0.05). The arrow shows the shift in COD for CRE sign change between the two models.

rized in Table 2 are the discrepancies in terms of CRE at both observational sites.

It is useful at this point to discuss some of the potential elements driving these differences. The larger discrepancies between the two models are likeliest ascribed to the parameterization of three specific parameters in the CP model: the first two, $\sigma *$ and $k *$ (Eq. 2 of Corti and Peter, 2009), are two approximated parameters for the Stefan-Boltzmann constant and the surface temperature exponent estimated from radiative calculations and used to calculate the outgoing longwave earth radiation. The last parameter, $\gamma *$ (again obtained from a regression analysis), is related to the asymmetry factor of cloud droplets and used to calculate the cloud reflectance of shortwave radiation (Eq. 11 in Corti and Peter, 2009). We speculate that, though the analysis is left to a future study on broader uncertainties in modeling ice radiative properties inherently with any model, these parameters are not the constants ascribed by $\mathrm{CP}$, but that their values instead change with respect to season and latitude. 

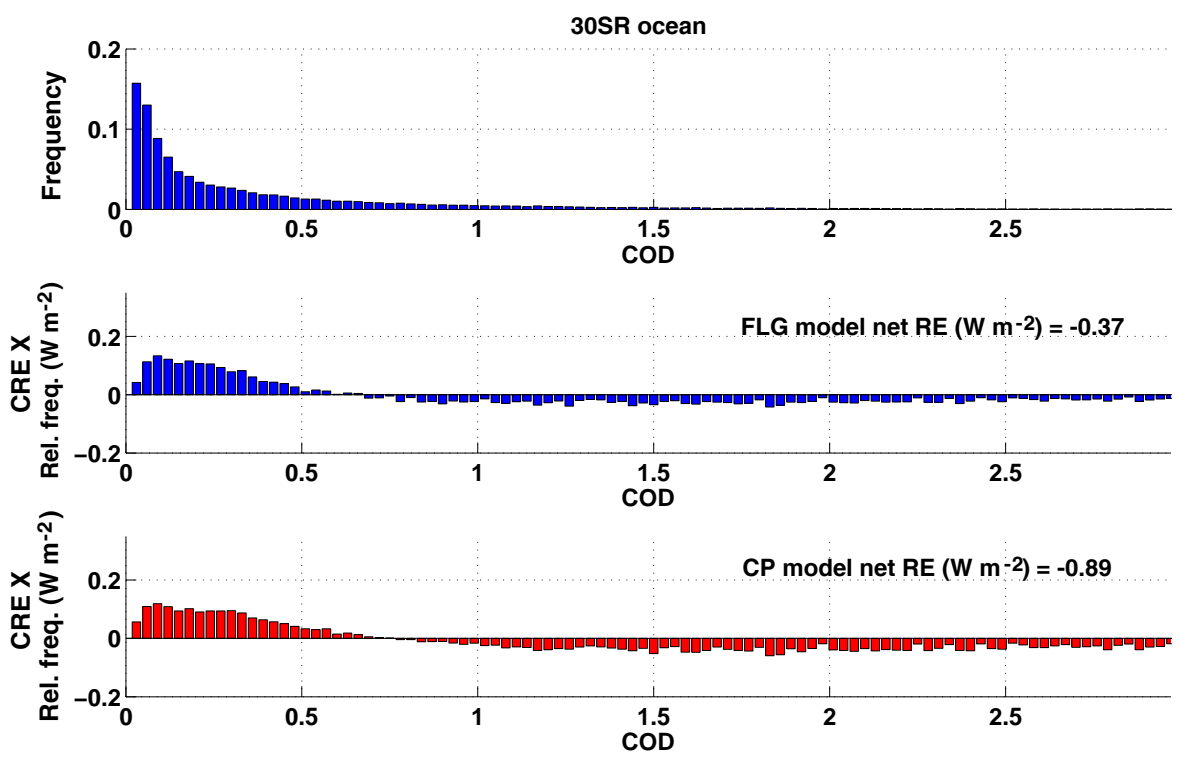

Figure 4. Same as Fig. 2, but over the ocean (albedo $=0.05)$.
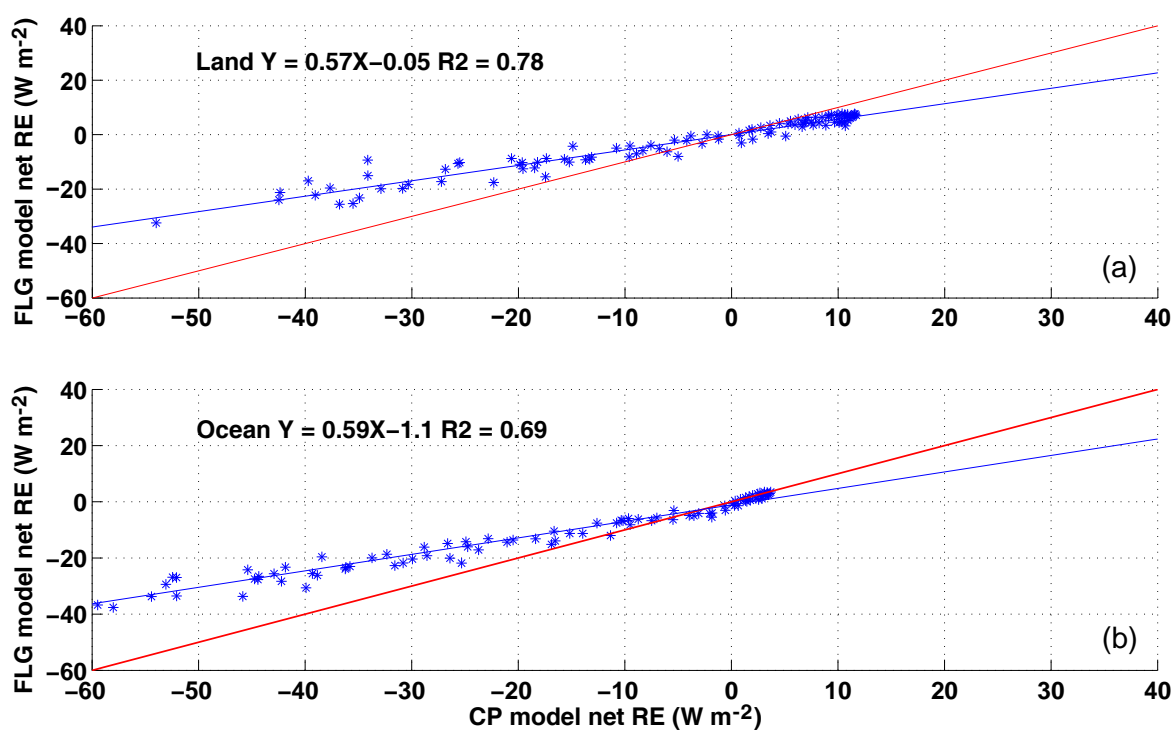

Figure 5. Scatter plot and linear regression for $30 \mathrm{sr}$ solution for FLG and CP CRE in 2010-2011 over land (a) and ocean (b).

The $20 \%$ relative model accuracy claimed in Corti and Peter (2009) may be verified for special conditions in tropical latitudes, where the three parameters discussed above are well optimized. However, that is clearly not found from our study. Corti and Peters (2009) expressly stated that they used fixed values for those three parameters (i.e., $\sigma *$ and $k *$ in Eq. 2 and $\gamma *$ in Eq. 11 in Corti and Peter, 2009) again using regression analysis, but this should not be the case, as net TOA cloud radiative forcing is very sensitive to those parameters. For example, varying water vapor concentrations in the atmosphere can be the responsible of a difference up to $25 \mathrm{Wm}^{-2}$ (for temperatures at the surface higher than $288 \mathrm{~K}$ ) in clear-sky earth longwave radiation at Singapore, as stated in Corti and Peter (2009; Fig. 1). In our analysis we verified that, over 1 year, the land surface temperature is higher than $288 \mathrm{~K} 66 \%$ of the time. For this reason, to assess whether land surface temperature is responsible for these larger discrepancies, we reproduced Fig. 6 (upper panel) masking out all cases corresponding with land surface temperatures higher than $288 \mathrm{~K}$ at Greenbelt (in Singapore those temperatures are mostly during nighttime). Shown in Fig. 7 are the results of the analysis. CP and FLG radiative transfer models in this range of temperature are in much better agreement (NET $\mathrm{CP}=-8.06 \mathrm{Wm}^{-2}$; NET FLG $-8.65 \mathrm{Wm}^{-2}$ ), within $6 \%$. 

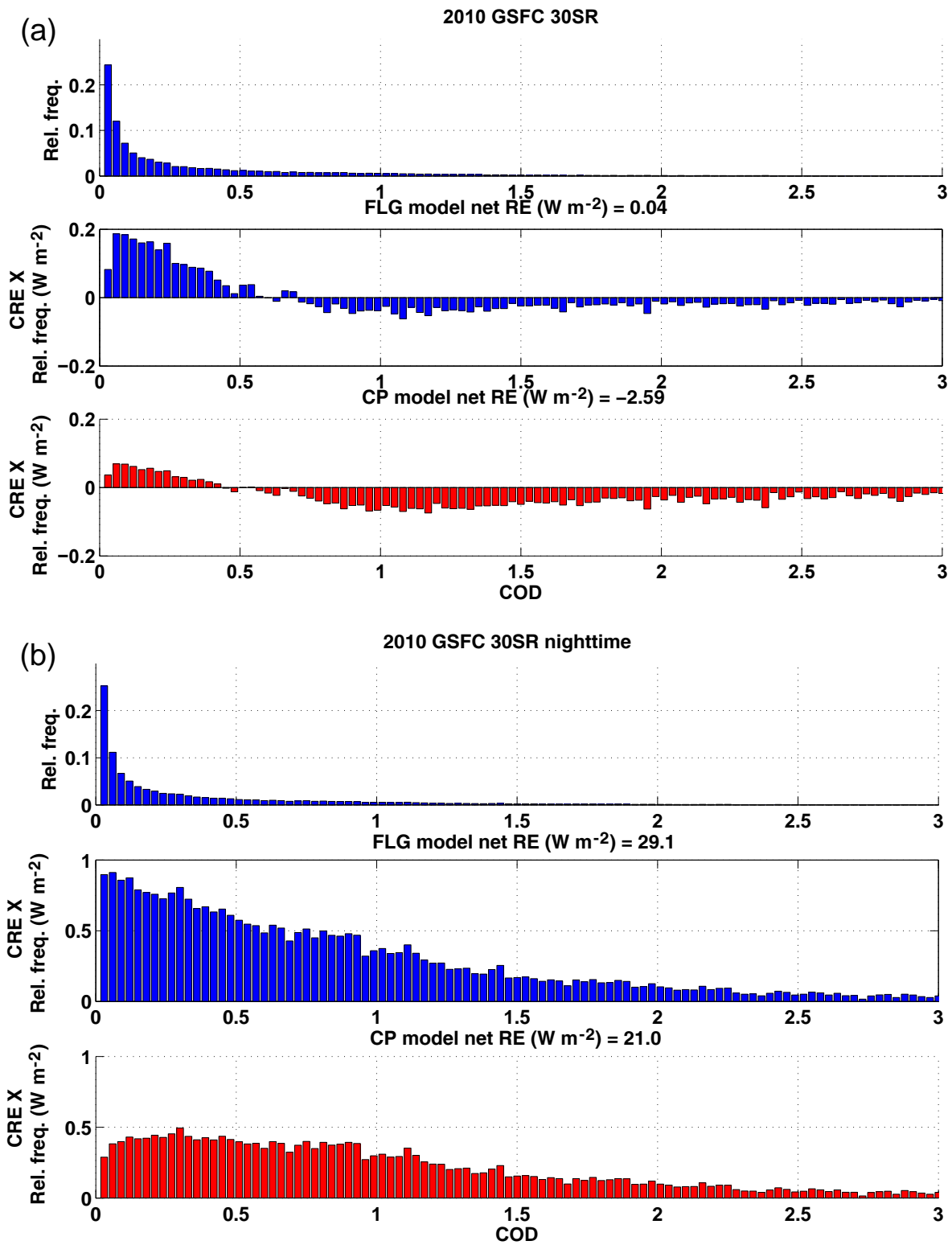

Figure 6. Analysis on 2010 dataset from MPLNET GSFC observational site for 30 sr solution daytime (a) and nighttime (b).

Table 2. Summary of principal CRE $\left(\mathrm{Wm}^{-2}\right)$ differences between FLG and CP radiative transfer model depending on year and on land/ocean.

\begin{tabular}{lll}
\hline CRE vs. COD & Ocean & Land \\
\hline SING 2010-2011 & 20 sr CP $=1.34$ FLG $=0.48(65 \%)$ & 20 sr CP $=4.20$ FLG $=2.98(30 \%)$ \\
& $30 \mathrm{sr} \mathrm{CP}=-0.89 \mathrm{FLG}=-0.37(58 \%)$ & $30 \mathrm{sr} \mathrm{CP}=4.43 \mathrm{FLG}=3.35(25 \%)$ \\
GSFC 2012 & & $30 \mathrm{sr} \mathrm{CP}=-2.59 \mathrm{FLG}=0.07$ \\
\hline
\end{tabular}

Choosing surface temperatures lower than $288 \mathrm{~K}$ is reducing the temperature gradient between the surface and cloud top, limiting the cloud thermal warming effect (see Eq. 6 of Corti and Peter, 2009). Moreover, lower temperatures are usually associated with a higher solar zenith angle, which implies stronger albedo effects. For this reason, in Fig. 7 the albedo effect is outweighing the capacity for cirrus cloud in trapping longwave radiation, with a net cooling effect estimated.

We advise that those looking to apply CP to long-term climate/cirrus cloud study should carefully analyze the rel- 

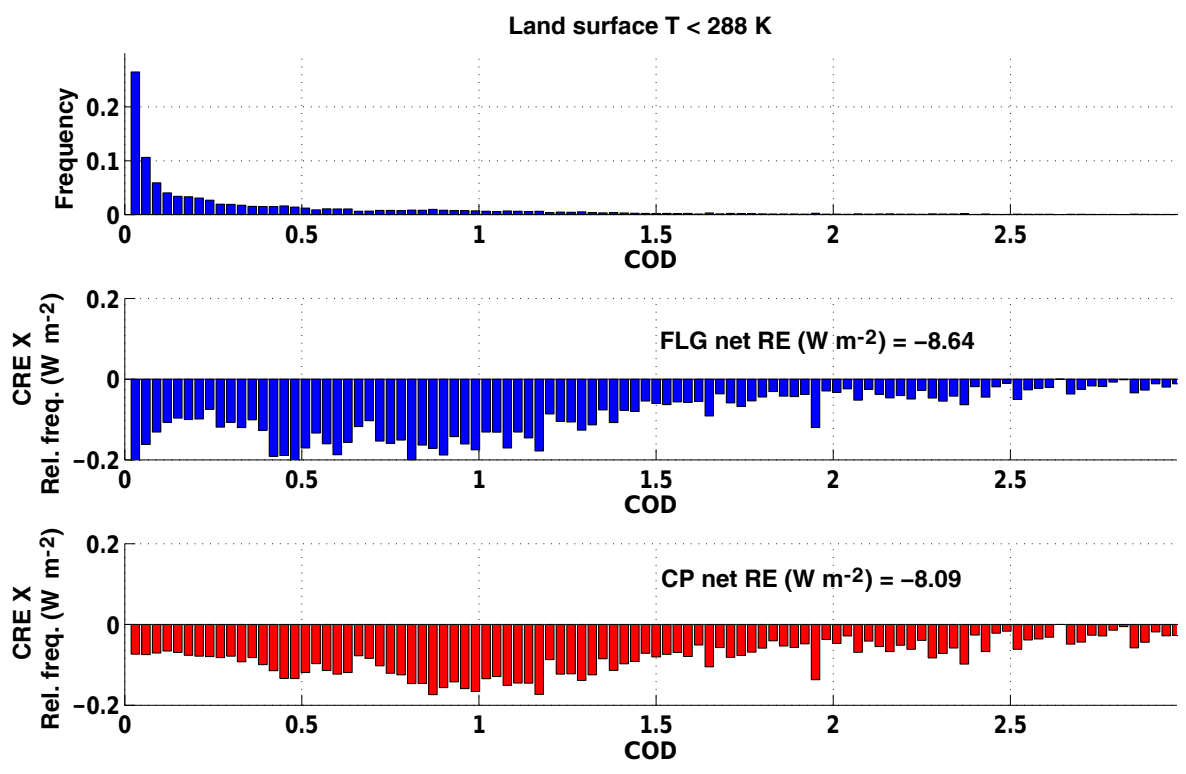

Figure 7. Same as Fig. 6, taking out those measurements with a land surface temperature $T_{\text {surf }}>288 \mathrm{~K}$.

evance of these settings to their given experiment before directly applying the model, especially when land surface temperatures are warmer than $288 \mathrm{~K}$.

\section{Conclusions}

Annual single-layer cirrus cloud top-of-the-atmosphere (TOA) radiative effects (CREs) calculated from the Corti and Peter (2009) radiative transfer model (CP) are compared with similar results from the more complex, and presumably more accurate, Fu-Liou-Gu (FLG) radiative transfer model. The CP model calculates CREs using a parameterization of longwave and shortwave fluxes that are derived from real measurements optimized for a tropical environment through a regression analysis to simplify the radiative calculations. Values for these parameterizations, as suggested in Corti and Peter (2009), lead to relative differences in TOA CRE that far exceed the stated $20 \%$ in the original paper. This includes parsing results out for daytime, nighttime, or diurnal averages. It is believed that specific parameterizations with the simplified model cannot be considered global constants, as originally defined for $\mathrm{CP}$, but that they should be carefully evaluated on single case basis for each experiment. Moreover we find that the land surface temperature is responsible for significant discrepancies when larger than $288 \mathrm{~K}$, because the original CP regression analysis is less accurate for larger temperatures. However, CP uses less input parameters compared with FLG, making it practically and computationally more efficient, particularly for large climate datasets. This is the first time, however, that the two models are compared using long-term cirrus clouds datasets, as opposed to synthetic datasets, with experiments conducted using NASA Micro-
Pulse Lidar datasets collected at Singapore in 2010 and 2011 (Lolli et al., 2017) and Greenbelt, Maryland, in 2012.

Net daytime TOA CRE was evaluated versus cloud optical depth (COD) for steps of 0.03 (COD range: $0-1$ ) at $20 \mathrm{sr}$ and for steps of 0.1 at $30 \mathrm{sr}$ (COD range: $0-3$ ) for Singapore datasets, while at $30 \mathrm{sr}$ for Greenbelt, Maryland. Our findings suggest that the difference in annual net TOA CRE between the two models approaches $65 \%$ in one experiment at Singapore. At Greenbelt, Maryland, the sign of the net annual daytime TOA CRE term differs, and the absolute difference varies between by nearly $2.5 \mathrm{Wm}^{-2}$. Differences in the sign of the net TOA forcing term, however, are most worrying. Since cirrus clouds are the only cloud that can exhibit daytime positive or negative net TOA CRE, subtle differences in absolute magnitude are less important than whether or not the clouds are inducing a cooling or forcing term in the TOA radiation budget.

In spite of this comparison, even if we reasonably speculate that FLG is the more accurate model overall, because of its relative complexity compared with $\mathrm{CP}$, we are still missing regular comparisons of FLG with real observational data. Thus, the practical gains to long-term application of a simplified model like CP cannot be overstated, given lower computational demands. However, we believe that the results from this study are noteworthy because they show that the differences between the two models are significant. With respect to cirrus annual net daytime TOA CRE, and given the perspective on their global distribution described by Campbell et al. (2016) and Lolli et al. (2017), these sensitivities can lead to completely different conclusions about global cirrus TOA forcing effects. Therefore, in future work, it is imperative for the community to continue understanding and refining the global parameterizations used in all radiative transfer models 
regarding cirrus. Continued intercomparisons between models with real observation at the ground (using flux measurements), in situ (aircraft measurements) and at TOA (using satellite-based measurements) remain critical interests.

Data availability. Data used for analysis are publicly available at https://mplnet.gsfc.nasa.gov.

Competing interests. The authors declare that they have no conflict of interest.

Acknowledgements. This study and the NASA Micro-Pulse Lidar Network (MPLNET) are supported by the NASA Radiation Sciences Program (H. Maring). James R. Campbell acknowledges the Naval Research Laboratory Base Program (BE033-03-45-T008-17) and support of NASA Interagency Agreement NNG15JA17P on behalf of MPLNET.

Edited by: T. von Clarmann

Reviewed by: two anonymous referees

\section{References}

Berry, E. and Mace, G. G.: Cloud properties and radiative effects of the Asian summer monsoon derived from A-Train data, J. Geophys. Res.-Atmos., 119, 9492-9508, https://doi.org/10.1002/2014JD021458, 2014.

Bourgeois, Q., Ekman, A. M. L., Igel, M. R., and Krejci, R.: Ubiquity and impact of thin mid-level clouds in the tropics, Nat. Commun., 7, 12432, https://doi.org/10.1038/ncomms12432, 2016.

Campbell, J. R., Lolli, S., Lewis, J. R., Gu, Y., and Welton, E. J.: "Daytime Cirrus Cloud Top-of-Atmosphere Radiative Forcing Properties at a Midlatitude Site and their Global Consequence", J. Appl. Meteorol. Clim., 55, 1667-1679, https://doi.org/10.1175/JAMC-D-15-0217.1, 2016.

Campbell, J. R., Hlavka, D. L., Welton, E. J., Flynn, C. J., Turner, D. D., Spinhirne, J. D., Scott, V. S., and Hwang, I. H.: Aerosol Lidar Observation at Atmospheric Radiation Measurement Program Sites: Instrument and Data Processing, J. Atmos. Ocean. Tech., 19, 431-442, 2002.

Comstock, J. M., Ackerson, T. P., and Mace, G. G.: Cirrus radiative properties in the tropical western pacific, Eleventh ARM Science Team Meeting Proceedings, Atlanta, Georgia, 19-23 March, 2001.

Corti, T. and Peter, T.: A simple model for cloud radiative forcing, Atmos. Chem. Phys., 9, 5751-5758, https://doi.org/10.5194/acp9-5751-2009, 2009.

Dionisi, D., Keckhut, P., Liberti, G. L., Cardillo, F., and Congeduti, F.: Midlatitude cirrus classification at Rome Tor Vergata through a multichannel Raman-Mie-Rayleigh lidar, Atmos. Chem. Phys., 13, 11853-11868, https://doi.org/10.5194/acp-1311853-2013, 2013.
Fu, Q. and Liou, K. N.: On the correlated $k$-distribution method for radiative transfer in nonhomogeneous atmospheres, J. Atmos. Sci., 49, 2139-2156, 1992.

Fu, Q., Liou, K. N., Cribb, M., Charlock, T. P., and Grossman, A.: Multiple scattering parameterization in thermal infrared radiative transfer, J. Atmos. Sci., 54, 2799-2812, https://doi.org/10.1175/15200469(1997)054<2799:MSPITI>2.0.CO;2, 1997.

Gu, Y., Farrara, J., Liou, K. N., and Mechoso, C. R.: Parameterization of cloud-radiation processes in the UCLA general circulation model, J. Climate, 16, 3357-3370, 2003.

Gu, Y., Liou, K. N., Ou, S. C., and Fovell, R.: Cirrus cloud simulations using WRF with improved radiation parameterization and increased vertical resolution, J. Geophys. Res., 116, D06119, https://doi.org/10.1029/2010JD014574, 2011.

Heymsfield, A., Winker, D., Avery, M., Vaughan, M., Diskin, G., Deng, M., Mitev, V., and Matthey, R.: Relationsips between ice water content and volume extinction coefficient from in situ observations for temperatures from $0^{\circ}$ to $-86^{\circ} \mathrm{C}$ : Implications for spaceborne lidar retrievals, J. Appl. Meteorol. Clim., 53, 479$505,2014$.

Immler, F., Treffeisen, R., Engelbart, D., Krüger, K., and Schrems, O.: Cirrus, contrails, and ice supersaturated regions in high pressure systems at northern mid latitudes, Atmos. Chem. Phys., 8, 1689-1699, https://doi.org/10.5194/acp-8-1689-2008, 2008.

IPCC: Climate Change 2013: The Physical Science Basis. Contribution of Working Group I to the Fifth Assessment Report of the Intergovernmental Panel on Climate Change, edited by: Stocker, T. F., Qin, D., Plattner, G.-K., Tignor, M., Allen, S. K., Boschung, J., Nauels, A., Xia, Y., Bex, V., and Midgley, P. M., Cambridge University Press, Cambridge, United Kingdom and New York, NY, USA, 1535 pp., https://doi.org/10.1017/CBO9781107415324, 2014.

Khvorostyanov, V. I. and Sassen, K.: Cirrus Cloud Simulation Using Explicit Microphysics and Radiation, Part I: Model Description, J. Atmos. Sci., 55, 1808-1821, 1998.

Kienast-Sjögren, E., Rolf, C., Seifert, P., Krieger, U. K., Luo, B. P., Krämer, M., and Peter, T.: Climatological and radiative properties of midlatitude cirrus clouds derived by automatic evaluation of lidar measurements, Atmos. Chem. Phys., 16, 7605-7621, https://doi.org/10.5194/acp-16-7605-2016, 2016.

Kothe, S., Dobler, A., Beck, A., and Ahrens, B.: The radiation budget in a regional climate model, Clim. Dynam., 36, 1023-1036, 2011.

Kuo-Nan, L.: Influence of Cirrus Clouds on Weather and Climate Processes: A Global Perspective, Mon. Weather Rev., 114, 1167 1199, 1986.

Lewis, J. R., Campbell, J. R., Welton, E. J., Stewart, S. A., and Haftings, P. C.: Overview of MPLNET version 3 cloud detection, J. Atmos. Ocean. Tech., 33, 2113-2134, 2016.

Liou, K.-N.: The influence of cirrus on weather and climate processes: A global perspective, Mon. Weather Rev., 114, 1167-1199, https://doi.org/10.1175/15200493(1986)114<1167:IOCCOW>2.0.CO;2, 1986.

Lolli, S., Campbell, J. R., Lewis, J. R., Gu, Y., Marquis, J. W., Chew, B. N., Liew, S., Salinas, S. V., and Welton, E. J.: Daytime Top-of-the-Atmosphere Cirrus Cloud Radiative Forcing Properties at Singapore, J. Appl. Meteorol. Clim., 56, 1249-1257, https://doi.org/10.1175/JAMC-D-16-0262.1, 2017. 
Lolli S., Lewis, J., Campbell, R., Gu, Y., and Welton, E.: Cirrus Cloud Radiative Characteristics from Continuous MPLNET Profiling at GSFC in 2012, Óptica pura y aplicada, 49,1-6, https://doi.org/10.7149/OPA.49.1.1, 2016.

Lolli, S., Welton, E. J., and Campbell, J. R.: Evaluating light rain drop size estimates from multiwavelength micropulse lidar network profiling, J. Atmos. Ocean. Tech., 30, 2798-2807, https://doi.org/10.1175/JTECH-D-13-00062.1, 2013.

Lolli, S., Welton, E. J., Campbell, J. R., Eloranta, E., Holben, B. N., Chew, B. N., and Salinas, S. V.: High Spectral Resolution Lidar and MPLNET Micro Pulse Lidar aerosol optical property retrieval intercomparison during the 2012 7-SEAS field campaign at Singapore, Proc. SPIE 9246, Lidar Technologies, Techniques, and Measurements for Atmospheric Remote Sensing X, 92460C, 20 October 2014, https://doi.org/10.1117/12.2067812, 2014.

Min, M., Wang, P., Campbell, J. R., Zong, X., and Li, Y.: Midlatitude cirrus cloud radiative forcing over China”, J. Geophys. Res., 115, D20210, https://doi.org/10.1029/2010JD014161, 2010.

Nazaryan, H., McCormick, M. P., and Menzel, W. P.: Global characterization of cirrus clouds using CALIPSO data, J. Geophys. Res., 113, D16211, https://doi.org/10.1029/2007JD009481, 2008.

Pani, S. K., Wang, S.-H., Lin, N.-H., Tsay, S.-C., Lolli, S., Chuang, M.-T., Lee, C.-T., Chantara, and Yu, J.-Y.: Assessment of aerosol optical property and radiative effect for the layer decoupling cases over the northern South China Sea during the 7-SEAS/Dongsha Experiment, J. Geophys. Res.-Atmos., 121, 4894-4906, https://doi.org/10.1002/2015JD024601, 2016.
Sassen, K. and Campbell, J. R.: A Midlatitude Cirrus Cloud Climatology from the Facility for Atmospheric Remote Sensing, Part I: Macrophysical and Synoptic Properties, J. Atmos. Sci., 58, 481496, 2001.

Sassen, K. and Cho, B. S.: Subvisual-Thin Cirrus Lidar Dataset for Satellite Verification and Climatological Research, J. Appl. Meteorol., 31, 1275-1285, https://doi.org/10.1175/15200450(1992)031<1275:STCLDF>2.0.CO;2, 1992.

Sassen, K., Wang, Z., and Liu, D.: Global distribution of cirrus clouds from CloudSat/Cloud-Aerosol Lidar and Infrared Pathfinder Satellite Observations (CALIPSO) measurements, J. Geophys. Res., 113, D00A12, https://doi.org/10.1029/2008JD009972, 2008.

Soden, B. J. and Donner. L. J.: Evaluation of a GCM cirrus parameterization using satellite observations, J. Geophys. Res., 99, 14401-14413, https://doi.org/10.1029/94JD00963, 1994.

Wang, S. H., Tsay, S., Lin, N., Chang, S., LI, C., Welton, E. J., Holben, B. N., Hsu, N. C., Lau, W. K., Lolli, S., Kuo, C., Chia, H., Chiu, C., Lin, C., Bell, S. W., Ji, Q., Hansell, R. A., Sheu, G., Chi, K., and Peng, C.: Origin, transport, and vertical distribution of atmospheric pollutants over the northern South China Sea during the 7SEAS/Dongsha experiment, Atmos. Environ., 78, 124-133, 2012.

Welton, E. J., Voss, K. J., Quinn, P. K., Flatau, P. J., Markowicz, K., Campbell, J. R., Spinhirne, J. D., Gordon, H. R., and Johnson, J. E.: Measurements of aerosol vertical profiles and optical properties during INDOEX 1999 using micropulse lidars, J. Geophys. Res., 107, INX2 18-1-INX2 18-20, 2002. 